\title{
ASSESSMENT OF THE TECHNICAL QUALITY OF ROOT CANAL TREATMENT IN PRE-CLINICAL ENDODONTIC TRAINING COMPARING ARTIFICIAL TEETH TO EXTRACTED NATURAL HUMAN TEETH
}

\author{
Ruaa A. Alamoudi* and Omar Fahim**
}

\begin{abstract}
Introduction: Extracted natural human teeth were used exclusively for preclinical endodontic training. However, an alternative method involves the use of artificial teeth aiming to overcome the limitations in natural teeth. This study aimed to radiographically evaluate the technical quality of preclinical single root canal treatments performed by undergraduate dental students using two alternative models; artificial teeth and extracted natural human teeth.
\end{abstract}

Materials and methods: Cross-sectional study, 228 single rooted teeth in academic years 2017- 2018 were obtained from the preclinical practice of undergraduate program in endodontics at the school of dentistry, King Abdulaziz University, Jeddah, Saudi Arabia. Four observers were asked to independently evaluate the radiographic quality of the root canal fillings according to three parameters: Filling length, density (homogeneity), and taper of the filling in the root canals.

Results: There were no significant correlation between the type of teeth and all three parameters; length, density, and taper of the root canals fillings. In addition, there was no statistically significant difference between adequacy of the root canals fillings and the type of teeth (P. value: 0.455 ). Extracted natural human teeth showed overall $10 \%$ adequate filling, $77.7 \%$ moderately filling, and $12 \%$ poorly filling. Meanwhile, artificial plastic teeth showed overall $13 \%$ adequate filling, $81.6 \%$ moderately filling, and $5 \%$ poorly filling.

Conclusion: Artificial teeth might be suitable for preclinical endodontic training but cannot totally substitute the requirement to learn with extracted natural human teeth as part of preclinical endodontic training. They could be incorporated with natural teeth.

KEYWORDS: Preclinical endodontic training, radiographic assessment, quality of root canal filling, extracted natural human teeth, artificial plastic teeth.

* Assistant Professor of Endodontics, Faculty of Dentistry, King Abdulaziz University, Jeddah, Saudi Arabia

** Professor of Endodontic, Cairo Egypt, Faculty of Oral \& Dental Medicine, Cairo University 


\section{INTRODUCTION}

In dental education programs, it is important to have a comprehensive hands-on pre-clinical training courses before student exposure to patient. ${ }^{[1]}$ Training courses are important step of learning in dental schools as they ensure students to gain expertise and develop manual skills essential to clinical practice. ${ }^{[2]}$

For centuries, extracted natural human teeth were most commonly used for preclinical endodontic training. However, these teeth had some drawbacks. The possibility of spreading infection from this organ to the student or dental staff members is high ${ }^{[3]}$ Thus, dental staff members who use extracted natural human teeth are potentially exposed to infectious organisms that may cause harm. For that, all dental staff members must follow infection control protocol guidelines. ${ }^{[3]}$ Moreover, the use of disinfectant agent such as sodium hypochlorite or hydrogen peroxide may cause some changes in the dental tissues making it difficult to be prepared or tested. ${ }^{[3-5]}$ Additionally, obtaining extracted natural human teeth became a difficult process. These limitations, along with ethical factors, have stimulated the development of artificial teeth for endodontic teaching purposes..$^{[2,6-10]}$

In the last few decades, different artificial models had been introduced to the market for endodontic training and replace extracted natural human teeth. This replacement is justified for the current conservative concept of maintaining natural teeth, which directly interferes with tooth extraction and makes it difficult to obtain. In addition, it is related to ethics committees' recommendations regarding teeth source, since many teeth are gained from dental offices without any official record..$^{[2,11]}$

Simulated root canals made in clear resin and placed in static manikin jaws or phantom heads ${ }^{[10}$, 12] are considerd another learning tool to substitute the extracted natural human teeth and mimic a reallife condition. ${ }^{[13]}$ In addition, the use of simulated root canals made of clear resin blocks permit a standardized length, diameter, and curvature in all teeth leading to validated assessment through their uniformity. ${ }^{[8]}$ However, dentin hardness, internal and external anatomy of artificial teeth do not accurately replicate the extracted natural human teeth. Also the lack of radioopacity do not allow the students to develop technical skills related to radiographic interpretation. As a result, researchers thought to fabricate artificial teeth with anatomical and physical characteristics resemble the dental tissues. $^{[2,6-8]}$

Lately, artificial teeth models had been made of opaque resin to replace the characteristic of natural teeth for teaching several endodontic treatment techniques. ${ }^{[2]}$

Although the similarities between artificial teeth and extracted natural human teeth are often emphasized, evaluation of the use of artificial teeth has been limited. ${ }^{[2]}$ Number of issues should be resolved if extracted natural human teeth are to be replaced with artificial ones in preclinical endodontic training.

\section{Aim of the study}

This study aimed to radiographically evaluate the technical quality of preclinical single root canal treatments performed by undergraduate dental students at King Abdulaziz University, Jeddah, Saudi Arabia using two different models; artificial plastic teeth made of clear resin and natural extracted human teeth. The technical quality of root canals fillings is determined by its length in relation to the apex, by its homogeneity, and by its taper.

\section{Hypothesis}

The quality of root canal fillings in artificial teeth is not differ from extracted natural human teeth.

\section{MATERIAL AND METHOD}

In this retrospective cross-sectional study, 228 single rooted teeth were obtained from the preclinical practice of undergraduate students at the school of dentistry, King Abdulaziz University, 
Jeddah, Saudi Arabia in academic year 2017- 2018.

The study was approved from research ethics committee of the Faculty of Dentistry, King Abdulaziz University reference number (031-2-18).

The obtained teeth consisted of 108 extracted natural human single rooted teeth and 120 artificial single rooted plastic teeth. Teeth that collected were the last two anterior teeth performed by fourth year undergraduate dental students. All the undergraduate students underwent extensive laboratory training courses on biomechanical and filling techniques. Undergraduate dental students possessed the same level of knowledge and practical experience of root canal treatment; using the step-back technique. They were taught by the instructors to use at least files number 15 for initial working length determination via conventional radiographs. After determination of the working length, the master apical file was set at minimum of number 30 , Gates Glidden drills number 1-3 were used as orifice openers and after the root canals were instrumented by files number 20-25. Passive step-back technique was carried out using patency file (\#10 or 15) and copious canal irrigation was recommended to the students. The canals were irrigated by $1 \%$ sodium hypochlorite during root canal treatment. All the teeth were obturated using the cold lateral condensation filling technique utilizing the gutta-percha (DENTSPLY, DeTrey, Konstanz, Germany- ISO standard) and AH-26 sealer (DENTSPLY, DeTrey, Konstanz, Germany). It is important to mention that all the teeth were held in plaster of Paris gypsum blocks containing a very thin layer of wax to ensure immobility before biomechanical preparation was initiated.

A post-obturation radiograph was taken with the receptor, X-ray tube and tooth position were kept constant. The radiographic procedure was performed using a dental X-ray unit (Siemens Aktiengesellschaft, Germany) at $50 \mathrm{kVp}, 8 \mathrm{~mA}$ and 0.01 $\mathrm{s}$ exposure time. The post-obturation radiograph showed the complete length of the root and the periapical area.
Four observers; two endodontic consultants, and two dental interns interpreted the images. Initially, all four observers independently evaluated the images. The results were then compared, and a final agreement was reached. In case of disagreement, a discussion meeting took place to reach final agreement. Before evaluation, the observers participated in calibration training; which consisted of 75 randomly selected periapical radiographs of endodontically treated incisors and premolars.

The observers used a digital softwareCS imaging version 7 (Carestream Health, Inc. 2009) to evaluate the root canals fillings. The observers were free to use and perform all the options in the software; such as brightness, contrast adjustment and magnification. No time limit was set for viewing the images.

The observers were asked to evaluate the radiographic quality of the fillings according to a criteria defined in Table 1. As in other similar studies, ${ }^{[14-16]}$ the filling quality was assessed based on three parameters: root canal fillings length, density (homogeneity) of fillings, and taper of root canals fillings.

A root canal filling was considered acceptable (total score: 6) only when the length, density and tapering of the root canal filling were adequate (three scores of 2). Fillings with total scores of 0-2 and 3-5 were considered to be poor and moderate, respectively.

\section{Data presentation and statistical analyses}

Data were analyzed using SPSS software, version 20.0 (SPSS Inc., Chicago, USA). Descriptive analysis was performed separately for each parameter. Chi square test was used to compare the artificial teeth versus the extracted natural human teeth with respect to length of fillings (adequate, under-fill, over-fill,flushed), Density (several voids, few voids, no void), and tapering of root canals fillings (tapered, semi-tapered, no taper). A total adequacy scoring (poor, moderate, and acceptable) was also recorded. The $P$ value was set to be 0.05 . 
TABLE (1) Criteria followed for evaluation of root canal fillings

\begin{tabular}{|l|l|c|}
\hline Parameter & Definition & Score \\
\hline $\begin{array}{l}\text { Length of root canal } \\
\text { filling }\end{array}$ & $\begin{array}{l}\text { Root filling ending >1 mm short of the radiographic apex (under -filling) } \\
\text { Root filling ending beyond the radiographic apex (over- filling) } \\
\text { Root filling ending at the radiographic apex (tip- to- tip) } \\
\text { Root filling ending 0.5-1 mm short of the radiographic apex (adequate) }\end{array}$ & 0 \\
& & 0 \\
Density of root canal \\
filling & Inhomogeneous root filling with several visible voids & 0 \\
& Root filling with few visible voids & 1 \\
Taper of root canal fill- & Not consistently tapered from the apex to the coronal part & 2 \\
ing & Semi- tapered ( irregular or parallel) & 0 \\
& Consistently tapered from the apex to the coronal part (adequate) & 1 \\
\hline
\end{tabular}

\section{RESULTS}

In all, 228 teeth were collected in academic year 2017- 2018 from preclinical practice of undergraduate program in endodontics at the school of dentistry, King Abdulaziz University, Jeddah, Saudi Arabia.46.8\% of these teeth are extracted natural human teeth and $51.9 \%$ are artificial. When length, tapering and density of the fillings are acceptable, a root canal filling is considered adequate.

Table (2) shows the relation between type of teeth and the quality of the root canals fillings. There were no significant correlation between type of teeth and all three parameters; Length, density, and taper of root canals fillings. Overall, there was no significant differance between the length of root canals fillings and the type of teeth (P. value: 0.190$)$. Natural teeth and artificial teeth were filled adequately(0.5-1 $\mathrm{mm}$ from radiographic apex) in $68.5 \%$ and $71.6 \%$ of the cases respectively. The relationship between the density of the root canals fillings and the type of teeth was not statistically significant (P. value: $0.061)$. Natural teeth showed $58 \%$ with few voids meanwhile artificial teeth showed 68\% with few voids The relationship between the type of the teeth and root canals tapers were also not statistically significant (P. value: 0.294). Root canals fillings were tapered adequately in both natural and artificial teeth; $67.5 \%$ and $73.3 \%$ of the cases respectively.

Table (3) demonstrates that in both groups the overall lincidence of under fillings; short than 1 $\mathrm{mm}$ from radiographic apex; is $11.3 \%$, beyond the radiographic apex is $2.2 \%$, at the radiographic apex is $16 \%$, and $0.5-1 \mathrm{~mm}$ from radiographic apex is $69.3 \%$. Table (4) shows that the overall incidence of several voids is 18.2 , few voids is 62.8 , and no voids is $17.7 \%$ in both groups of teeth. Table (5) revealed that the overall percentage of no tapered is $5.2 \%$, semi-tapered is $23.8 \%$, and tapered is $69.7 \%$.

Looking to the overall adequacy (Table 6), there was no statistically significant difference between adequacy of root canals fillings and type of teeth (P. value: 0.455$)$. Natural teeth showed overall $10 \%$ adequate filling, $77.7 \%$ moderately filling, and $12 \%$ poorly filling. However, artificial plastic teeth showed overall $13 \%$ adequate filling, $81.6 \%$ moderately filling, and $5 \%$ poorly filling.

TABLE (2) Relation between radiographic quality of the root canal fillings and type of teeth

\begin{tabular}{|l|c|c|}
\hline Parameters & $\begin{array}{c}\text { Chi square test } \\
\text { (P. value) }\end{array}$ & Df \\
\hline Length of root canal filling & 0.190 & 1 \\
\hline Density of root canal filling & 0.061 & 1 \\
\hline Taper of root canal filling & 0.294 & 1 \\
\hline
\end{tabular}


TABLE (3) Overall length of root canal filling parameters for both natural and artificial teeth; N (\%)

\begin{tabular}{|l|c|c|c|}
\hline Length of root canal filling & Natural & Artificial & Total \\
\hline Root filling ending $>\mathbf{1} \mathbf{~ m m}$ short of the radiographic apex & $16(14.8 \%)$ & $10(8.3)$ & $26(11.3 \%)$ \\
\hline Root filling ending beyond the radiographic apex & $3(2.7 \%)$ & $2(1.6 \%)$ & $5(2.2 \%)$ \\
\hline Root filling ending at the radiographic apex & $15(13.8 \%)$ & $22(18.3 \%)$ & $37(16 \%)$ \\
\hline Root filling ending $\mathbf{0 . 5 - 1} \mathbf{~ m m}$ short of the radiographic apex & $74(68.5 \%)$ & $86(71.6 \%)$ & $160(69.3 \%)$ \\
\hline
\end{tabular}

TABLE (4) Overall density of root canal filling parameters for both natural and artificial teeth; $\mathrm{N}(\%)$

\begin{tabular}{|l|c|c|c|}
\hline Density of root canal filling & Natural & Artificial & Total \\
\hline Inhomogeneous root filling with several visible voids & $27(25 \%)$ & $15(12.5 \%)$ & $42(18.2 \%)$ \\
\hline Root filling with few visible voids & $63(58.3 \%)$ & $82(68.3 \%)$ & $145(62.8 \%)$ \\
\hline No void present in the root filling & $18(16.6 \%)$ & $23(19.1 \%)$ & $41(17.7 \%)$ \\
\hline
\end{tabular}

TABLE (5) Overall taper of root canal filling parameters for both natural and artificial teeth; $\mathrm{N}(\%)$

\begin{tabular}{|l|c|c|c|}
\hline Taper of root canal filling & Natural & Artificial & Total \\
\hline Not consistently tapered from the apex to the coronal part & $7(6.4 \%)$ & $5(4.1 \%)$ & $12(5.2 \%)$ \\
\hline Semi- tapered & $28(26 \%)$ & $27(22.5 \%)$ & $55(23.8 \%)$ \\
\hline Consistently tapered from the apex to the coronal part & $73(67.5 \%)$ & $88(73.3 \%)$ & $161(69.7)$ \\
\hline
\end{tabular}

TABLE (6) Correlation between overall root canal adequacy and type of teeth

\begin{tabular}{|c|c|c|}
\hline Adequacy & Natural teeth N (\%) & Artificial teeth N (\%) \\
\hline Poor & $13(13 \%)$ & $98(81.6 \%)$ \\
\hline Moderate & $84(77.7 \%)$ & $16(13 \%)$ \\
\hline Adequate & $11(10 \%)$ & 0.455 \\
\hline Chi -square test & & 6 \\
\hline df & & \multicolumn{2}{|c|}{} \\
\hline
\end{tabular}




\section{DISCUSSION}

This study aimed to compare the technical quality of root canal treatment using extracted natural human teeth and artificial teeth in preclinical endodontic practice, King Abdulaziz University, Jeddah, Saudi Arabia. Preclinical endodontic training course is an integral part of the endodontic curriculum to assure that dental student are competent and exposed to the concept of root canal treatment before exposure to patients. Some universities used only extracted natural human teeth in their preclinical training to ensure that student is gaining experience in exposing to the real anatomical variation. Since complain of using the natural teeth has been received from students, changes in this concept has been introduced. Nassri et al ${ }^{[2]}$ introduce the artificial resin teeth and they reported their acceptance among professors in endodontics .Since it has been commonly used artificial teeth in restorative preparation and restoration in preclinical training, ${ }^{[10,17]}$ most universities start to use both artificial and natural teeth for their endodontic preclinical training. ${ }^{[18]}$

Natural and artificial teeth both have some limitations in endodontic training. In natural teeth most of the complaint was because the difficulty in obtaining these teeth, the presence of anatomical variation, and difficulty of treating natural teeth. Thus, assessment of the individual performance may be difficult. ${ }^{[19-21]}$ In addition, preparing natural teeth are time consuming including examination, case selection, faculty approval and sterilisation before they can be mounted in the dento-form.

Spenst and Kahn ${ }^{[22]}$ advocated the advantages of using artificial teeth for endodontic training. Artificial teeth are standardized allowing for valid assessment of each student individually since the canal anatomy is simple and no anatomical variations, they also available in large amount and allow students to visualize and criticize their biomechanical preparation and canal filling steps to enable improve their skills and to better understand the endodontic concept. ${ }^{[23]}$ However, artificial teeth do not mimic the complexity and anatomical variation of natural teeth.

Although the efficacy of artificial teeth replacing extracted natural human teeth during preclinical endodontic training has not been investigated, treatment quality of both groups were radiographically evaluated in this study.

In our pre-clinical endodontic training course, modification to combine artificial teeth and extracted natural human teeth were achieved. The idea of including artificial teeth was to control the limitations of natural teeth. It was important to mention that minimizing the variables by controlling lectures' quantity and practical exercises requirements in both groups to enable to evaluate the influence of the teaching approach. The extracted natural human teeth and the artificial teeth were both used as a training model and both were mounted in an individual form (dentec)in a phantom head.

The primary aim of this study was to assess the technical quality of root canal treatment comparing natural and artificial teeth and if training on artificial teeth can replace training on natural teeth. Accordingly ,the result of the present study did not show any significant difference between both natural and artificial teeth in terms of working length, density, and tapering of the root canals fillings. The results of our study is in accordance with previous studies which concluded that the use of artificial teeth did not have negative effect on the technical quality of roots fillings, students' skills, and root filling outcomes during their preclinical endodontic training course. Both groups achieved a higher percentage of acceptable root fillings. ${ }^{[19,24,25]}$

If assessing separate items, we further found that students in the both groups; Natural teeth and artificial teeth estimated the working length accurately (68.5\% and $71.6 \%$ respectively). Root canal filling 
length is one of the important criteria to evaluate the quality of the root canal treatment. ${ }^{[24-26]}$ The criteria utilized in this study were obtained from observations made by Schaeffer et al. ${ }^{[27]}$ They performed a meta-analysis literature regarding the optimal filling length and reported that the highest success rates of root canals were obtained if the canal was filled 0-1 $\mathrm{mm}$ short of the radiographic apex.Regarding the density of root canal filling, both groups showed a few visible voids with no significant difference between both types. However artificial teeth showed little high percentage $(68.3 \%)$ of visible voids compared to natural teeth $(58.3 \%)$ this could be due to the radiopacity of artificial teeth that should be improved to correspond to that of extracted natural human teeth. Regarding the taper of root canal filling, although there were no significant different between both groups, artificial teeth showed more consistent taper $(73.3 \%)$ compared to natural teeth $(67.5 \%)$.

Although the obturation procedure itself was perceived as mostly similar to it in natural teeth. Proving that manufacturing material of the plastic teeth was the major hindrance. One study reported difficulty in instrumentation of artificial teeth due to the loss of tactile sensation, which increased the risk of procedural errors. ${ }^{[21]}$ Another study by Nassri et al., ${ }^{[2]}$ who examined artificial teeth and stated that most endodontists favourably accepted the artificial teeth, except for the texture and hardness of the root canal. This directly affected instrumentation of the canal.

This study has number of strengths and limitations. All assessments were blinded to group allocation, decreasing the risk of detection bias. However, sample size was relatively small, leading to limited power and a subsequent risk of type II error. In addition, our results are only valid with regard to the specific artificial teeth used, other artificial teeth might be more or less suitable for preclinical training giving the possibility of different pulp chamber and root canal fulfillment, internal and ex- ternal anatomy, and dentin (resin) hardness. Lastly, this study assessed the quality of root canal filling in preclinical condition and not on a real patients' oral cavity ignoring other important factors such as tooth position, tooth angulation, and range of mouth opening. Thus, it should be noted that future studies should aim to additionally demonstrate the effects of different training methods on clinical competency of students.

\section{CONCLUSION}

To conclude, the suitability of artificial teeth for preclinical endodontic training had no significant difference from extracted natural human teeth in term of the quality of root canal filling. Therefore, artificial teeth might be suitable for preclinical endodontic training but cannot substitute the requirement to learn with natural teeth as part of preclinical endodontic training course. They could be incorporated with natural teeth, especially due to their availability and standardisation. Furthermore, their physical characteristics through the manufacturing material should be enhanced to become more closely resemble natural tissues (enamel \& dentin) and promote their wider use and acceptance.

\section{ACKNOWLEDGMENT:}

The authors would like to thank dental interns; Afrah Alharbi,GhadaFarie who participated in this study for learning purpose. The authors also would like to thank the students of preclinical endodontic training in King Abdulaziz University, Jeddah, Saudi Arabia in academic year 2017- 2018 for participating in preparing and collecting the teeth.

\section{Financial support and sponsorship:}

Nil.

\section{Conflict of interest:}

There are no conflict of interest. 


\section{REFERENCES}

1. Qualtrough AJ, Whitworth JM, Dummer PM. : Preclinical endodontology: an international comparison. Int Endod J. 1999;32(5):406-14.

2. Nassri MR, Carlik J, da Silva CR, Okagawa RE, Lin S. : Critical analysis of artificial teeth for endodontic teaching. Journal of Applied Oral Science : revista FOB. 2008;16(1):43-9.

3. DeWald JP.: The use of extracted teeth for in vitro bonding studies: a review of infection control considerations. Dent Mater. 1997;13(2):74-81.

4. Kumar M, Sequeira PS, Peter S, Bhat GK. : Sterilisation of extracted human teeth for educational use. Indian J Med Microbiol. 2005;23(4):256-8.

5. Hope CK, Griffiths DA, Prior DM. : Finding an alternative to formalin for sterilization of extracted teeth for teaching purposes. J Dent Educ. 2013;77(1):68-71.

6. Peterson WR.: A technique for preparing an artificial tooth for endodontic access preparation. J Endod. 1980;6(3):490-4.

7. Kahn H. : A preclinical Dentec for teaching endodontic procedures. J Endod. 1983;9(11):506-9.

8. Dummer PM, Alodeh MH, al-Omari MA. : A method for the construction of simulated root canals in clear resin blocks. Int Endod J. 1991;24(2):63-6.

9. Reader CM, Kleier DJ, College C, Bujanda-Wagner S.: Anatomical artificial teeth for teaching preclinical endodontics. J Dent Educ. 1994;58(3):229-32.

10. Suvinen TI, Messer LB, Franco E.: Clinical simulation in teaching preclinical dentistry. Eur J Dnt Educ. 1998;2(1):25-32.

11. JCP. I. : Bank of human teeth. Curitiba, Brazil: EditoraMaio. 2003.

12. Jackson AP, Tidmarsh BG.: Simulation models for teaching endodontic surgical procedures. Int Endod J. 1993;26(3):198-200.

13. Herbert J, Buchmann G.: New multipurpose endodontic device developed in Germany for use in predoctoral and continuing dental education and science. J Dent Educ. 2012;76(6):759-64.

14. Er O, Sagsen B, Maden M, Cinar S, Kahraman Y. : Radiographic technical quality of root fillings performed by dental students in Turkey. Int Endod J. 2006;39(11):867-72.

15. Roman-Richon S, Faus-Matoses V, Alegre-Domingo T, Faus-Llacer VJ. : Radiographic technical quality of root canal treatment performed ex vivo by dental students at Valencia University Medical and Dental School, Spain. Med Oral Patol Oral Cir Bucal. 2014;19(1):e93-7.

16. Barrieshi-Nusair KM, Al-Omari MA, Al-Hiyasat AS. : Radiographic technical quality of root canal treatment performed by dental students at the Dental Teaching Center in Jordan. J Dent. 2004;32(4):301-7.

17. Esser C, Kerschbaum T, Winkelmann V, Krage T, Faber FJ.: A comparison of the visual and technical assessment of preparations made by dental students. Eur J Dent Educ. 2006;10(3):157-61.

18. Sonntag D, Barwald R, Hulsmann M, Stachniss V. : Preclinical endodontics: a survey amongst German dental schools. Int Endod J. 2008;41(10):863-8.

19. Tchorz JP, Brandl M, Ganter PA, Karygianni L, Polydorou $\mathrm{O}$, Vach $\mathrm{K}$, et al. : Pre-clinical endodontic training with artificial instead of extracted human teeth: does the type of exercise have an influence on clinical endodontic outcomes? Int Endod J. 2015;48(9):888-93.

20. dos SLD, de SOF, Scarparo RK, Vier-Pelisser FV, Morgental RD, Waltrick SB, et al.: Preparation time and perceptions of Brazilian specialists and dental students regarding simulated root canals for endodontic teaching: a preliminary study. J Dent Educ. 2015;79(1):56-63.

21. Al-Sudani DI, Basudan SO.: Students' perceptions of preclinical endodontic training with artificial teeth compared to extracted human teeth. Eur J Dent Educ. 2017;21(4):e72-e5.

22. Spenst A, Kahn H. : The use of a plastic block for teaching root canal instrumentation and obturation. J Endod. 1979; 5(9):282-4.

23. LaTurno SA, Corcoran JF, Ellison RL. : An evaluation of a teaching aid in endodontics. J Endod. 1984;10(10):507-11.

24. Eleftheriadis GI, Lambrianidis TP. : Technical quality of root canal treatment and detection of iatrogenic errors in an undergraduate dental clinic. Int Endod J. 2005;38 (10):725-34.

25. Khabbaz MG, Protogerou E, Douka E. : Radiographic quality of root fillings performed by undergraduate students. Int Endod J. 2010;43(6):499-508.

26. Ricucci D, Langeland K. : Apical limit of root canal instrumentation and obturation, part 2. A histological study. Int Endod J. 1998;31(6):394-409.

27. Schaeffer MA, White RR, Walton RE. : Determining the optimal obturation length: a meta-analysis of literature. J Endod. 2005;31(4):271-4. 